\title{
PEMENUHAN KEBUTUHAN SPIRITUAL CARE PASIEN RAWAT INAP
}

\author{
Mardiani, Hermansyah
Politeknik Kesehatan Kementerian Kesehatan Bengkulu, Jurusan Keperawatan, Jalan Indragiri Nomor 03 Padang Harapan Bengkulu \\ mardiani21daud@gmail.com
}

\begin{abstract}
Nurses who have the ability to identify and understand the spiritual aspects of the patient, will be able to carry out spiritual fulfillment and knowing how spiritual beliefs can affect the life of every individual. The purpose of this research is the perception of nurses correlation with the fulfillment of the spiritual care of patients in inpatient hospitals Dr.M. Yunus Bengkulu. The type of this research is analityc with cross sectional design. The Research sample is nurses inpatient ward of RSUD Dr. M. Yunus Bengkulu who numbered 83 nurses taken with total sampling technique. Research done at eight wards hospitals Dr. M Yunus Bengkulu for two months. Collecting data using a questionnaire. Quantitative data analysis is univariate and bivariate with uji chi-square at $\alpha 5 \%$. The results showed that there was a significant relationship between the perception of nurses and spiritual fulfillment of inpatient care in hospitals Dr. M.Yunus Bengkulu (p : 0.022) with OR 3.107 (95\% CI : 1.265 to 7.630), which means nurses have perceptionless chance three times to apply the spiritual care that is less favorable than that good perception. To the Hospital Dr. M. Yunus Bengkulu expected for the provision of facilities and additional skills for nurses in the inpatient room about the importance of spiritual fulfillment as well as the necessary care program to improve the perception of nursing care, especially for spiritual fulfillment inpatients.
\end{abstract}

Keywords : Perception, nurses, spiritual care

\begin{abstract}
Abstrak : Perawat yang memiliki kemampuan untuk mengidentifikasi dan memahami aspek spiritual pasien, akan dapat melaksanakan pemenuhan kebutuhan spiritual dan mengetahui bagaimana keyakinan spiritual dapat mempengaruhi kehidupan setiap individu. Tujuan penelitian adalah mengidentifikasi hubungan persepsi perawat dengan pemenuhan kebutuhan spiritual care pasien di ruang rawat inap RSUD Dr.M. Yunus Bengkulu. Jenis penelitian adalah analitik dengan pendekatan cross sectional. Sampel penelitian adalah perawat di ruang rawat inap RSUD M. Yunus yang berjumlah 83 orang yang diambil dengan dengan teknik total sampling. Penelitian dilakukan di delapan bangsal RSUD Dr. M Yunus Bengkulu selama dua bulan. Pengumpulan data menggunakan kuisioner. Analisis data secara kuantitatif yaitu univariat dan bivariate dengan uji chi-square pada $\alpha 5 \%$. Hasil penelitian menunjukkan bahwa ada hubungan yang bermakna antara persepsi perawat dengan pemenuhan spiritual care pasien rawat inap di RSUD Dr. M.Yunus Bengkulu (p : 0.022) dengan nilai OR 3,107 (95\% CI : 1,265-7,630), yang berarti perawat yang berpersepsi kurang memiliki peluang tiga kali untuk menerapkan spiritual care yang kurang baik dibandingkan dengan perawat yang berpersepsi baik. Kepada pihak RSUD Dr. M. Yunus Bengkulu diharapkan untuk pemberian fasilitas dan penambahan keterampilan bagi perawat di ruang inap tentang pentingnya pemenuhan kebutuhan spiritual care serta perlu di-lakukan program persamaan persepsi untuk meningkatkan asuhan keperawatan terutama terhadap pemenuhan kebutuhan spiritual pasien rawat inap.
\end{abstract}

Kata Kunci : Persepsi, perawat, spiritual care

Perawat sebagai tenaga kesehatan yang profesional memiliki kesempatan yang paling besar untuk memberikan asuhan keperawatan yang komprehensif dengan membantu klien untuk memenuhi kebutuhan dasar yang holistik yaitu biopsiko-sosio dan spiritual (Potter \& Perry, 2009). Aspek spiritual merupakan salah satu komponen yang ada dalam keperawatan menyeluruh (Holistik Nursing) pada diri 
individu yang dapat mengharmonisasi aspek fisik (body), pikiran/psikologi (mind), dan spirit (spirit) (Dossey, 2005). Aspek spiritual dapat mendorong seseorang untuk melakukan yang terbaik ketika menghadapi keadaan stres, emosional, penyakit, atau bahkan menjelang kematian, dengan demikian pasien dapat mencapai kualitas hidup yang terkait dengan kesehatannya (Mc Sherry, 1998; Monod et al 2012; Rajinkan, 2006).

Kebutuhan aspek spiritual sangat penting selama periode sakit karena ketika sakit, energi seseorang akan berkurang dan spirit orang tersebut akan terpengaruhi, oleh karena itu kebutuhan spiritual pasien perlu dipenuhi (Potter \& Perry, 2005). Pasien meng-ungkapkan bahwa kebutuhan spiritual mereka adalah kebutuhan akan makna, tujuan dan harapan dalam hidup, hubungannya dengan Tuhan, praktek spiritual, kewajiban agama, hubungan dengan sesama dan hubungan dengan perawat (Hodge et al, 2011).

Spiritual sebagai konsep dua dimensi, yaitu dimensi vertikal dan dimensi horizontal. Dimensi vertikal adalah hubungan dengan Tuhan atau Yang Maha Tinggi yang menuntun kehidupan seseorang. Dimensi horizontal adalah hubungan seseorang dengan diri sendiri, dengan orang lain, dan dengan lingkungan. Terdapat hubungan terus-menerus antara dua dimensi tersebut. Perawat sebagai tenaga kesehatan yang profesional mempunyai kesempatan paling besar untuk memberikan pelayanan kesehatan khususnya pelayanan asuhan keperawatan yang komprehensif dengan membantu klien memenuhi kebutuhan dasar yang holistik. Asuhan keperawatan yang diberikan oleh perawat tidak bisa terlepas dari aspek spiritual yang merupakan bagian integral dan interaksi perawat dengan klien. Perawat berupaya untuk membantu memenuhi kebutuhan spiritual klien sebagai bagian dari kebutuhan menyeluruh klien, antara lain dengan memfasilitasi kebutuhan spiritual klien, walaupun perawat dan klien tidak mempunyai keyakinan spiritual atau keagamaan yang sama (Hamid, 2009).

Besarnya peran aspek spiritual bagi kesehatan, pemberian pelayanan spiritual merupakan hal yang penting yang perlu dilakukan. Perawat harus berupaya membantu memenuhi kebutuhan spiritual sebagai bagian dari kebutuhan menyeluruh pasien antara lain dengan memfasilitasi pemenuhan kebutuhan spiritual. Perawat harus mampu mendapatkan informasi dari pasien tentang spiritual dan prakteknya yang dapat disediakan di rumah sakit, membantu untuk mengungkapkan persepsinya mengenai makna dalam keadaan sakit, menerapkan prinsip membantu pasien melaksanakan konsepkonsep spiritual dalam satu konteks keperawatan. Perawat yang memiliki kemampuan untuk mengidentifikasi dan memahami aspek spiritual pasien, akan dapat melaksanakan pemenuhan kebutuhan spiritual dan mengetahui bagaimana keyakinan spiritual dapat mempengaruhi kehidupan setiap individu ( Hamid, 2008; Potter \& Perry, 2005).

Penelitian yang dilakukan Hubbel et al (2006) terhadap 65 perawat ditemukan bahwa meskipun mayoritas perawat mengakui spiri-tual care merupakan bagian penting dari praktek keperawatan, namun 73 $\%$ perawat mengatakan tidak rutin memberikan spiritual care pada pasien, bahkan penelitian Strana-han (2001, dalam Hubbel et al, 2006) menunjukkan $57 \%$ perawat tidak pernah me-laksanakan spiritual care. Mc Sherry (1998) juga menemukan hanya $39,9 \%$ perawat memberikan spiritual care pada pasien.

Konsep spiritual dalam keperawatan sudah menjadi dasar keperawatan, tetapi dalam prakteknya seringkali diabaikan. Hal ini disebabkan oleh beberapa alasan yaitu kurangnya perhatian perawat terhadap spiritualnya sendiri, adanya kendala waktu, kurangnya pengetahuan terkait spiritual care, kurang jelasnya perbedaan antara agama dan spiritualitas, terkadang pasien beda kepercayaan dengan perawat, dan 
kurangnya bimbingan dari manajer perawat (Amankaa et al, 2009). Pendapat ini didukung dengan hasil penelitian Rohman (2009) bahwa selain faktor-faktor diatas masih terdapat faktor lainnya yaitu : karakteristik perawat, kesejah-teraan atau kesehatan spiritual perawat, kesadaran akan spiritualitas diri perawat, pemeliharaan spiritualitas diri perawat, perawat masih bingung dengan perannya terkait pemberian spiritual care, dan perawat merasa tidak sesuai dengan profesinya. Dalam praktik keperawatan, perawat kurang memperhatikan kebutuhan spiritual karena perawat kurang memahami tentang kebutuhan spiritual dan manfaatnya terhadap kesehatan dan penyembuhan penyakit pasien. Hal pertama yang harus diperhatikan perawat adalah peningkatan persepsi dan sikap tentang perawatan spiritual dan manfaatnya, sehingga dalam praktik pemberian asuhan keperawatan spiritual pasien dapat terpenuhi (Hamid 2008).

Kenyataan di lapangan, ada kalanya antara perawat yang satu dengan perawat yang lain mempunyai persepsi yang berbeda dalam memberikan kebutuhan spiritual pasien yang menyebabkan ada sikap keraguan dari perawat untuk dapat memfasilitasi kebutuhan spiritual yang diperlukan oleh pasien. Sikap yang muncul dari perawat bukannya memotivasi pasien dengan menggunakan substansi keagamaan pasien melainkan informasi data keagamaan pasien, misalnya hanya mengkaji keyakinan yang dianut pasien, kegiatan keagamaan pasien (Peterson \& Nelson dalam Perry \& Potter 2005). Perawat sering ragu dalam mendiskusikan masalah spiritual care pasien, ragu karena perawat merasa kurang yakin dalam berbagi spiritualitas dengan pasien (Perry \& Potter 2005).

Penelitian ini bertujuan untuk mengetahui hubungan antara persepsi perawat dengan pemenuhan kebutuhan spiritual care pasien rawat inap di RSUD $M$. Yunus Bengkulu.

\section{BAHAN DAN CARA KERJA}

Jenis penelitian yang digunakan adalah analitik dengan rancangan cross sectional. Populasi dalam penelitian ini adalah keseluruhan perawat di ruang rawat inap RSUD M. Yunus pada tahun 2016. Sampel dalam penelitian ini diambil dengan teknik total populasi yakni sebanyak 83 responden. Instrumen penelitian menggunakan kuesioner. Analisis data secara univariat dan bivariat dengan menggunakan uji chi-square pada $\alpha$ $5 \%$.

\section{HASIL}

\section{Analisis Univariat}

Analisis univariat pada penelitian ini akan karakteristik serta persepsi responden dengan pemenuhan kebutuhan spiritual care pasien yang dapat dilihat pada tabel 1 s.d. tabel 3.

Tabel 1. Distribusi Responden Berdasarkan Jenis Kelamin, Pendidikan, dan Status Pernikahan

\begin{tabular}{|c|c|c|c|}
\hline No. & Variabel & $\begin{array}{c}\text { Frekuensi } \\
\text { (f) }\end{array}$ & $\begin{array}{c}\text { Persentase } \\
(\%)\end{array}$ \\
\hline \multirow{4}{*}{1.} & Umur & & \\
\hline & $\leq 34$ tahun & 14 & 58,3 \\
\hline & $>30$ tahun & 10 & 41,7 \\
\hline & Jumlah & 83 & 100 \\
\hline \multirow[t]{4}{*}{2.} & Jenis Kelamin & & \\
\hline & Laki-laki & 10 & 12,0 \\
\hline & Perempuan & 73 & 88,0 \\
\hline & Jumlah & 83 & 100 \\
\hline \multirow[t]{4}{*}{3.} & Pendidikan & & \\
\hline & Vokasional & 26 & 31,3 \\
\hline & Profesional & 57 & 68,7 \\
\hline & Jumlah & 83 & 100 \\
\hline \multirow[t]{4}{*}{4.} & Status Perkawinan & & \\
\hline & Menikah & 79 & 95,2 \\
\hline & Belum Menikah & 4 & 4,8 \\
\hline & Jumlah & 83 & 100 \\
\hline \multirow[t]{4}{*}{5.} & Lama Kerja & & \\
\hline & $<10$ tahun & 39 & 47,0 \\
\hline & $\geq 10$ tahun & 44 & 53,0 \\
\hline & Jumlah & 83 & 100 \\
\hline
\end{tabular}

Tabel 1. menunjukkan bahwa sebagian besar perawat $(88,0 \%)$ dengan jenis kelamin perempuan, lebih dari sebagian $(68,7 \%)$ dengan pendidikan profesional, dan hampir seluruh $(95,2 \%)$ sudah menikah, lebih dari sebagian responden $(61,4 \%)$ berusia lebih dari 34 tahun dan sebagian responden (53\%) bekerja lebih dari 10 tahun. 
Tabel 2. Persepsi responden tentang Spiritual Care

\begin{tabular}{ccc}
\hline $\begin{array}{c}\text { Persepsi tentang } \\
\text { Spiritual Care }\end{array}$ & $\begin{array}{c}\text { Frequency } \\
(\mathbf{f})\end{array}$ & $\begin{array}{c}\text { Persentase } \\
(\boldsymbol{\%})\end{array}$ \\
\hline Kurang & 40 & 48.2 \\
Baik & 43 & 51.8 \\
Total & 83 & 100.0 \\
\hline
\end{tabular}

Berdasarkan tabel 2. dapat diketahui bahwa sebagian responden $(51,8 \%)$ memiliki persepsi yang baik tentang spiritual care.

Tabel 3. Pemenuhan Spiritual Care Pasien

\begin{tabular}{ccc}
\hline $\begin{array}{c}\text { Pemenuhan Spiritual } \\
\text { Care Pasien }\end{array}$ & $\begin{array}{c}\text { Frequency } \\
(\mathbf{f})\end{array}$ & $\begin{array}{c}\text { Persentase } \\
(\boldsymbol{\%})\end{array}$ \\
\hline Kurang & 38 & 45.8 \\
Baik & 45 & 54.2 \\
Total & 83 & 100.0 \\
\hline
\end{tabular}

Tabel 3. menunjukkan bahwa lebih dari sebagian responden $(54,2 \%)$ memiliki pemenuhan spiritual care yang baik.

\section{Analisis Bivariat}

Analisis bivariat digunakan untuk menjelaskan hubungan persepsi perawat dengan pemenuhan spiritual care pasien di Ruang Rawat Inap RSUD Dr. M. Yunus Bengkulu, yang dapat dilihat pada tabel 4 . berikut.

Tabel 4. Hubungan Persepsi Responden dengan Pemenuhan Spiritual Care Pasien

\begin{tabular}{|c|c|c|c|c|c|c|}
\hline \multirow{2}{*}{$\begin{array}{l}\text { Per- } \\
\text { sepsi }\end{array}$} & \multicolumn{2}{|c|}{$\begin{array}{c}\text { Pemenuhan Spir- } \\
\text { itual Care }\end{array}$} & \multirow{2}{*}{$\begin{array}{l}\text { To- } \\
\text { tal }\end{array}$} & \multirow{2}{*}{$\mathbf{X}^{2}$} & \multirow{2}{*}{$\mathbf{p}$} & \multirow{2}{*}{$\begin{array}{c}\text { OR } \\
(95 \% \\
\text { CI) }\end{array}$} \\
\hline & Kurang & Baik & & & & \\
\hline Kurang & 24 & 16 & 40 & & & \\
\hline & $60,0 \%$ & $40 \%$ & 100 & 5,2 & 0,0 & $\begin{array}{r}5,101 \\
(1,265-\end{array}$ \\
\hline Baik & $\begin{array}{c}14 \\
32,6 \%\end{array}$ & $\begin{array}{c}29 \\
67,4 \%\end{array}$ & $\begin{array}{c}43 \\
100\end{array}$ & 30 & 22 & $7,630)$ \\
\hline
\end{tabular}

Berdasarkan hasil penelitian pada tabel 4. dapat diketahui bahwa dari 40 orang responden dengan persepsi kurang baik terdapat 24 orang $(60 \%)$ dengan pemenuhan spiritual care yang kurang, dan dari 43 responden yang berpersepsi baik terdapat terdapat 14 orang $(32,6 \%)$ dengan pemenuhan berspiritual care baik. Hasil penelitian menunjukkan nilai $p: 0.022<0,05$, yang berarti ada hu-bungan yang bermakna antara persepsi perawat dengan pemenuhan spiritual cara. Nilai OR 3,107 (95\% CI : 1,2657,630), yang berarti perawat yang berpersepsi kurang memiliki peluang tiga kali un- tuk menerapkan spiritual care yang kurang baik dibandingkan dengan perawat yang berpersepsi baik.

\section{PEMBAHASAN}

Hasil penelitian secara univariat didapatkan bahwa sebagian besar perawat $(88,0 \%)$ dengan jenis kelamin perempuan, lebih dari sebagian $(68,7 \%)$ dengan pendidikan profesional, dan hampir seluruh $(95,2 \%)$ sudah menikah, lebih dari sebagian responden $(61,4 \%)$ berusia lebih dari 34 tahun dan sebagian responden $(53 \%)$ bekerja lebih dari 10 tahun. Untuk persepsi responden sebagian responden $(51,8 \%)$ memiliki persepsi yang baik dan dalam pemenuhan kebutuhan spi-ritual pasien didapatkan lebih dari sebagian responden $(54,2 \%)$ memiliki pemenuhan spi-ritual care yang baik. Setelah dilakukan analisis bivariat, hasil penelitian menunjukkan bahwa ada hubungan yang bermakna antara persepsi perawat dengan pemenuhan spiritual care pasien rawat inap di RSUD Dr. M.Yunus Bengkulu ( $p: 0.022$ ) dengan nilai OR 3,107 (95\% CI : 1,265-7,630), yang berarti perawat yang berpersepsi kurang me-miliki peluang tiga kali untuk menerapkan spiritual care yang kurang baik dibandingkan dengan perawat yang berpersepsi baik.

Penelitian ini sejalan dengan pendapat Wiwindaryati (2006) yang melakukan penelitian tentang persepsi perawat pelaksana terhadap aspek spiritual dalam asuhan keperawatan di rumah sakit. Hasil penelitiannya menunjukkan bahwa perawat memahami dengan baik bahwa klien membutuhkan pemenuhan spiritual, perawat berperan sebagai pemberi asuhan keperawatan spritual dan perawat cukup memahami asuhan keperawatan spiritual. Puspita (2009) menyatakan bahwa sentuhan spiritual adalah aktivitas intim yang menjadi kebutuhan dasar manusia. Tanpa sentuhan spiritual, seseorang akan jauh lebih rentan terhadap depresi, stres, mudah gelisah, kehilangan kepercayaan diri dan kehilangan motivasi. Sentuhan spiritual memiliki banyak makna. Bisa berarti sesuatu yang 
dapat memberikan rasa nyaman, terhibur, atau bahagia. Menurut Aziz (2006), dukungan emosianal sebagai perilaku yang memberikan perasaan nyaman dan membuat individu percaya bahwa dia dikagumi, dihargai, dan dicintai dan bahwa orang lain bersedia memberiperhatian dan rasa aman.

Asumsi yang bisa peneliti paparkan bahwa selain persepsi perawat faktor keluarga juga sangat berperan dalam pemenuhan spiritual pasien, hal ini sejalan dengan teori menurut Potter \& Perry (2009), keluarga sangat berperan dalam pemenuhan kebutuhan spiritual pasien karena keluarga merupakan tempat pertama kali pasien memperoleh pengalaman dan pandangan hidup. Dari keluarga, individu belajar tentang Tuhan, kehidupan dan diri sendiri, sehingga dampak negatif dari tidak terpenuhinya kebutuhan spiritual yaitu distress spiritual dan dapat juga seseorang akan jauh lebih rentan terhadap depresi, stres, mudah gelisah, kehilangan kepercayaan diri dan kehilangan motivasi, yang mungkin dapat meng-akibatkan seseorang merasa sendiri dan terisolasi dari orang lain. Individu mungkin mempertanyakan nilai spiritual mereka, tujuan hidup, jalan hidup seluruhnya dari makna hidupnya (Craven \& Hirnle, 2009).

\section{DAFTAR RUJUKAN}

Aziz, A.H. (2006). Pengantar Kebutuhan Dasar Manusia Aplikasi Konsep dan Proses Keperawatan. Jakarta: Salemba Medika

Amankwaa, L., Jenkins, M., Trent, B.,\& Wikoff, K. (2009). The Positive Effects of Spirituality of Health, Well Being, and Life Satisfaction. Nursing Center Journal Issue, 40, 29-36.

Blais, K. K. , Hayes, J. S., \& Kozier, B. (2002). Praktek Keperawatan Professional. Jakarta: EGC.

Baldacchino DR. (2006). Nursing Competencies for spi-ritual care. Journal of Clinical Nursing.

Cavendish, R., Luise, B., Russo, D. (2004). Spiritual Perspectives of Nurses' in The United States Relevant to Education and Practice. Western Journal of Nursing Research, 26:1-16.

Chan, M. F. (2008). Factors Affecting Nursing Staff in Practicing Spititual Care. Journal of Clinical Nursing, 19, 2128-2136
Berdasarkan pembahasan yang telah diuraikan, meskipun hasil penelitian menunjukkan ada tingkat keeratan hubungan yang cukup antara persepsi perawat dengan peme-nuhan kebutuhan spiritual pasien, tetapi persepsi perawat dapat mempengaruhi pemenuhan kebutuhan spiritual pasien.

\section{KESIMPULAN}

Dapat disimpulkan bahwa sebagian res-ponden memiliki persepsi yang baik tentang spiritual care pasien, lebih dari sebagian res-ponden memiliki pemenuhan spiritual care yang baik terhadap pasien dan terdapat hu-bungan yang bermakna antara persepsi perawat dengan pemenuhan spiritual care (nilai $\mathrm{p}=0.022$ ) dan perawat yang berpersepsi kurang memiliki peluang tiga kali untuk menerapkan spiritual care yang kurang baik dibandingkan dengan perawat yang berpersepsi baik (OR : 3,107).

Pihak rumah sakit diharapkan dapat melakukan promosi, pemberian fasilitas dan penambahan keterampilan bagi perawat di ruang inap tentang pentingnya pemenuhan kebutuhan spiritual care serta perlu dilakukan program persamaan persepsi untuk meningkatkan asuhan keperawatan terutama terhadap pemenuhan kebutuhan spiritual pasien rawat inap.

Craven \& Hirnle. (2009). Fundamentals of Nursing Six Edition: Human Health and Function. Lippincot.

Dover, K., Bacon, R., \& Jane, T. (2001). Spiritual Care in Nursing Practice: A Close-up View. Journal of E-ducation and Practice, 5, 150-159.

Dossey,B.Keega,L.,\& Guzzetta,C. (2005). Holistic Nursing : A HandBook for Practice. Sudbury, Massachusetts : Jones and Bartlett.

Hamid, Y. (2008). Buku Ajar Spiritual dalam Keperawatan. Jakarta: Widya Medika.

Hamid, A.Y.S. (2009). Asuhan Keperawatan Kesehatan Jiwa Bunga Rampai. Jakarta. EGC. https://books.google.co.id/books?id. Diakses pada tanggal 23 November 2016.

Hidayat, Aziz Alimul. (2009). Metode Penelitian Keperawatan dan Teknis Analisis Data. Jakarta: Salemba Medika. 
Hubbel., Saral, L., Elizabeth, K., Barksdale, B., Debra, J., \& Parker, J. S. (2006). Spiritual Care Practices of Nurse Practitioners in Federally Designated Non Metropolitan Areas of North Carolina. Journal of the American Academy of Nurse Practitioners, 18, 85-91.

Kozier, Erb, Berman. Snyder. (2004). Fundamental of Nursing: Concepts, Process and Practice. New Jersey: Pearson Prentice Hall.

Mahmoodishan, G., Alhani, F., Ahmadi, F.,\& Kazemnejd, A. (2010). Iranian Nurses's Perceptions of Spiritual and Spiritual Care: A Qualitative Content Analysis Study. Journal of Medical Ethics and History of Medicine, 3, 88- 95.

McSherry, W. (1998). Nurses Perceptions of Spirituality and Spiritual Care. Nursing Standart, 13, 3640.

Meehan, T. (2012). Spirituality and Spiritual Care from a Careful Nursing Perspective. Journal of Clinical Management, 4, 1-11.

Notoatmodjo, Soekidjo. (2007). Kesehatan Masyarakat Ilmu dan Seni. Jakarta: Asdi Mahasatya.

Nursalam. 2008. Konsep dan Penerapan Metodologi Penelitian Ilmu Keperawatan: Pedoman Skripsi,
Tesis, dan Instrumen Penelitian Keperawatan, edk 2. Jakarta: Salemba Medika.

Potter, Patricia, A \& Perry, Anne Griffin. (2005). Buku Ajar Fundamental Keperawatan: Konsep, Proses, dan Praktik, vol.1 edk 4. Jakarta: EGC.

(2009). Fundamental of Nursing: Concept, Proses and Practice, Ed.7. Missouri: Mosby Year Book.

Puspita, I. (2009). Aplikasi Asuhan Keperawatan Spiritual Muslim di R. FIRDAUS III RS. Al-Islam. Bandung:

Rohman. (2009). Faktor-faktor yang Berhubungan dengan Pemberian Asuhan Spiritual oleh Perawat di RS Islam Jakarta. Thesis. Jakarta: Universitas Indonesia.

Speck, P., Higginson, I., Addington-Hall, J. (2004). Spi-ritual Needs in Health Care. 329:123.

Sunaryo. (2004). Psikologi untuk Keperawatan. Jakarta: EGC.

Siagian, Sondang. P. (1995). Teori Motivasi dan Aplikasinya. Jakarta: Rineka Cipta.

Wiwindaryati. (2006). Persepsi Perawat Pelaksana Terhadap Aspek Spiritual dalam Asuhan Keperawatan di RS Al-Islam Bandung. Journal Berita Ilmu Keperawatan. 